Sathyan, R. \& Couldridge, V.C.K. (2013). Female preference for blue in Japan blue guppies (Poecilia reticulate). Environmental Biology of Fishes, 96: 953 - 959. http://dx.doi.org/10.1007/s10641-012-0091-5

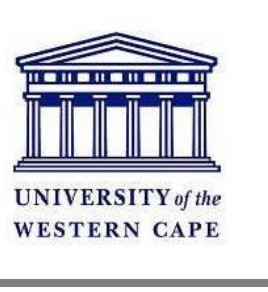

\title{
Female preference for blue in Japan blue guppies (Poecilia reticulata)
}

\author{
Rekha Sathyan and Vanessa C. K. Couldridge
}

\begin{abstract}
Guppies (Poecilia reticulata) are widely used as a model species in mate choice studies. Although native to South America, guppies have been introduced to natural water bodies in disparate regions of the globe. Here, for the first time, we examine guppies from one such introduced population in Japan where males have evolved a predominantly blue color pattern. Previous studies of wild-type guppies have shown blue to play a relatively minor role in the mate choice decisions of females compared to other traits, such as orange, and the importance of blue is not universally supported by all studies. The Japanese population therefore presents an ideal opportunity to re-examine the potential significance of blue as a mate choice cue in guppies. Mate choice experiments, in which female Japan blue guppies were given a choice between pairs of males that differed in their area of blue coloration but were matched for other traits, revealed that females prefer males with proportionately larger amounts of blue in their color patterns. We discuss possible factors, including sexual and ecological selection, which may have led to the evolution of unusually large areas of blue at the expense of other colors in Japan blue guppies. However, further studies are needed to distinguish between these scenarios.
\end{abstract}

\section{Introduction}

Guppies (Poecilia reticulata) are small and brightly colored fish native to South America and islands of the Caribbean. The color patterns of wild-type males are highly polymorphic and vary widely among populations, but generally consist of a combination of carotenoid (red, orange, and yellow) and melanin (black) pigments, that absorb certain wavelengths of light, and iridescent (blue, green, violet, and white) structural colors that scatter and reflect certain wavelengths (Bagnara et al. 2007; Price et al. 2008). These elements differ in size, position, shape, and intensity (Houde 1997). Numerous studies have demonstrated the significance of male color patterns to female mating preferences in both natural (Houde 1987; Houde and Endler 1990; Kodric-Brown 1993; Evans et al. 2004) and introduced (Brooks and Caithness 1995; Brooks and Endler 2001; Karino and Shinjo 2004) populations of guppies. In particular, these studies have provided overwhelming evidence in support of the role of size and saturation of carotenoid patches as major targets of mate choice (e.g., Houde 1987; Kodric-Brown 1989; Long and Houde 1989; Houde and Endler 1990), although the relative strength of this preference for orange does vary extensively among individuals (Kodric-Brown and Nicoletto 1996) and populations 
(Houde and Endler 1990; Endler and Houde 1995; Kemp et al. 2009). In addition to color, females may also evaluate other cues when selecting a mate, such as display rate (Farr 1980; Bischoff et al. 1985; Kodric-Brown 1993; Kodric-Brown and Nicoletto 1996), body size (Reynolds and Gross 1992; Karino and Matsunaga 2002), caudal fin size (Bischoff et al. 1985), dorsal fin size (Karino et al. 2011), gonopodium length (Brooks and Caithness 1995), and social cues (Godin et al. 2005). However, reported female preferences for individual size components may instead reflect an overall preference for a larger combined body and fin surface area (lateral projection area) (MacLaren and Fontaine 2012).

Besides orange, the relative importance of other components of the color pattern, such as melanin and iridescent colors, remains less certain, but they may be the focus of female mate choice decisions in at least some populations (Endler 1983; Kodric-Brown 1985, 1993; Kodric-Brown and Johnson 2002; Kemp et al. 2009). It is likely that the various elements that comprise the complex color patterns of male guppies work together to enhance attractiveness. For example, it is suggested that carotenoid and iridescent colors both function in female mate choice (Endler 1983; Kodric-Brown 1985) but assume different roles during courtship, with carotenoids attracting females from a distance and iridescent colors functioning more in the close-range assessment of displaying males (Endler 1983). Because iridescent colors change according to the direction of ambient light and viewing angle, animals are able to direct their visual signals towards an intended receiver, making them ideally suited to close-range communication (Doucet and Meadows 2009). However, because iridescent colors are extremely conspicuous at close ranges, they are generally reduced in guppy populations with high levels of predation (Endler 1978, 1980, 1983).

Iridescent (structural) coloration may serve multiple functions in the mate choice displays of animals. Many recent studies have demonstrated a link between male condition and iridescent color in a variety of taxa, including butterflies (Kemp et al. 2006; Kemp and Rutowski 2007), damselflies (Fitzstephens and Getty 2000), spiders (Lim and Li 2007), and birds (Doucet 2002; McGraw et al. 2002; Møller and Petrie 2002; Doucet and Montgomerie 2003; Hill et al. 2005). This provides strong evidence that iridescence serves as an honest signal of male quality. Furthermore, iridescence may play a role in signal amplification by enhancing the appearance and conspicuousness of other visual elements in the display (Doucet and Meadows 2009). This is achieved because iridescent colors tend to be brighter and more saturated than pigment-based colors, thus providing high contrasts with other color components and/or the background. The amount of iridescence has been shown to increase with age in guppies (Miller and Brooks 2005), in which case females choosing mates on the basis of iridescence may be selecting for older males with demonstrated survivorship.

Japan blue guppies represent a feral population of wild-type guppies introduced to a river in the Kanagawa prefecture of Japan. Since their discovery in the late 1980s, they have been widely used in artificial breeding for the aquarium trade due to their unusual coloration. Male Japan blue guppies are predominantly blue in color, especially towards the posterior half of the body. Orange and black spots are also present in the color pattern, but these are

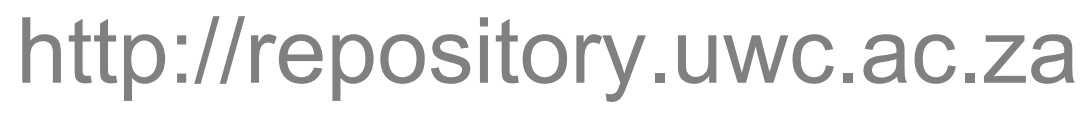


relatively small in size and number, and may even be absent in some individuals. This population thus provides an ideal opportunity to examine the role of blue in female mating preferences. Despite their uniqueness, there have been no previous mate choice studies conducted on Japan blue guppies, and the factors that have contributed to this deviation in color pattern remain unknown. The increased proportion of blue area at the expense of other colors could be due to founder effects, genetic drift, different ecological pressures, sexual selection, or a combination of the above.

Here, we provide an initial examination of female mating preferences in Japan blue guppies, to establish whether females favor males with greater amounts of blue in their color pattern.

\section{Materials and methods}

\section{Study animals}

All fish used in the experiment were laboratory-reared offspring (F1 or F2) of wild-caught parents that had been obtained from a local supplier. As the fish matured, males and females were separated to ensure that females were virgins, and therefore sexually responsive, when tested. Fish were housed communally in same-sex groups in aquaria measuring $900 \mathrm{~mm} \times 350 \mathrm{~mm}$, with a water level of $300 \mathrm{~mm}$. Each aquarium contained a corner water filter, water heater, and gravel substratum, and was fitted with a Sun-Glo fluorescent tube to simulate the energy spectrum of sunlight. Fish were maintained on a 12-h light-dark cycle with a combination of natural and artificial lighting. The temperature was maintained at $24-26^{\circ} \mathrm{C}$.

The guppies were fed flake food three times daily. Measuring male characters prior to the start of the female choice experiments, each male was photographed on both left and right sides using a digital camera (Canon 600D). Males were placed individually into a small glass container that restricted movement in order to allow photographs to be taken more easily. A section of ruler was included for scale. Males were positioned near a window so that the side being photographed was lit by natural lighting. The room also contained an overhead fluorescent bulb. Photographs were taken side-on at a distance of approximately $100 \mathrm{~mm}$. These conditions were kept constant for all images taken. From these photographs, NIH Image $J$ software (http://rsb.info. nih.gov/ij) was used to obtain measurements of total body area, area of blue coloration, body length, caudal fin length, number and area of orange spots, and number and area of black spots. Boundaries defining color areas were judged by eye. Color measurements were averaged between left and right sides, and relative area was calculated as the total area of color divided by the total body area. Based on the proportional amount of blue coloration, males were separated into two groups of equal number, representing males with relatively "more" (Group A) and relatively "less" (Group B) blue color relative to the median score. Males were subsequently housed individually in 5-l containers for the remainder of the experiment to allow for easy individual identification and to ensure that the males' recent social experience was similar. 


\section{Measuring female preference}

The experimental aquarium $(900 \mathrm{~mm} \times 350 \mathrm{~mm}$, with a water level of $300 \mathrm{~mm}$ ) was maintained as per the stock aquaria (see above), but was divided into three equal compartments, separated by clear glass partitions. The central compartment was further subdivided into three equal sections, demarcated on the outside of the aquarium for ease of recording the position of the female. Three sides of the aquarium were covered with tan paper to obtain a uniform background.

Female choice was tested by placing a female in the central compartment of the aquarium and giving her 20 min to acclimatize. After the acclimation period, two males (one from Group A and one from Group B) were randomly selected from each group and placed in the two end compartments of the aquarium. The trial was then recorded on a digital camcorder (Sony Handycam DCR - TRV608E). From the video recordings, the amount of time (s) spent by the female in each of the three demarcated areas was calculated to determine female preference for each male. Time spent in the proximity of a male has been demonstrated to be a reliable measure of female choice in guppies and other poeciliid fish (e.g., Bischoff et al. 1985; Kodric-Brown 1989, 1993; Walling et al. 2010). While males were reused in more than one experimental trial, the same combination of males was not repeated. Females $(n=20)$ were only used once. In order to control for potential bias towards one side of the tank, males from each group were alternately assigned to the left or right compartment in successive trials. Fish were fed 30 min before observations and each trial lasted $15 \mathrm{~min}$.

\section{Statistical analysis}

Data was first tested for normality using Shapiro-Wilk tests, and where data did not conform to a normal distribution, data was log-transformed. Student's $t$ tests were used to confirm that males in Groups A and B differed significantly in the amount of blue color, and to establish whether they also differed in any of the other measured characters, which may have influenced female preference. Pearson correlations were used to test for a relationship between the amounts of blue, orange, and black, body lengths and caudal fin length in males. A paired $t$ test (time as the dependent variable, group as the independent variable) was used to test for a difference in the amount of time that females spent near each of the two groups of males. To test whether any other male traits may have influenced female preference, a general linear model (GLM) was conducted, with the difference in the amount of time the female spent in the two choice sections as the dependent variable and differences in orange area, black area, body length, and caudal fin length between paired stimulus males as co-variates. All statistical analyses were carried out using IBM SPSS Statistics 20.0.0 (IBM2011).

\section{Results}

Males placed in Group A (more blue) had significantly larger amounts of blue in their color patterns than males in Group B (less blue). The two groups did not differ significantly in any other measured character (Table 1). A comparison of traits for the two groups is shown in Table 1. Correlations of male characters revealed that blue area was positively correlated

\section{http://repository.uwc.ac.za}


with caudal fin length only $(r=0.537, P=0.048)$. Body length and caudal fin length were also significantly correlated with each other $(r=0.582, P=0.029)$. All other correlations between measured male characters were non-significant. Because of the observed correlation between blue area and caudal fin length, an ANCOVA was performed with blue area as the dependent variable, group as the fixed factor, and caudal fin length as the covariate. This served to confirm whether blue was the only trait that differed significantly between males of the two groups. Results of this ANCOVA showed that blue differed significantly between the groups $\left(F_{1,37}=90.716, P<0.001\right)$, but caudal fin length did not $\left(F_{1,37}=0.063, P=0.803\right)$.

Results from the female choice trials showed that females spent significantly more time with males from Group A (more blue) than they did with males from Group B (less blue) ( $t_{19}$ $=2.587, P=0.014$ ) The amount of time females spent in each of the three sections of the choice tank is shown in Fig. 1. The results of the GLM showed that none of the other measured male characters significantly influenced female preference (black: $F_{1,15}=0.856$, $P=0.369$; orange: $F_{1,15}=0.213, P=0.651$; caudal fin: $F_{1,15}=1.338, P=0.265$; standard length: $\left.F_{1,15}=0.359, P=0.558\right)$.

\section{Discussion}

This study provides evidence on the critical role of blue coloration as a mate choice cue in Japan blue guppies. Our results show that males with a greater amount of blue in their color pattern were more attractive to females than males with less blue, as measured by the amount of time females spent close to them. Other measured male traits were not correlated with the amount of blue, with the exception of caudal fin length. However, males from the two groups did not differ significantly in caudal fin length, which suggests that females have a preference for blue that is independent of caudal fin length. The significance of blue in the color pattern of males of this population is underlined by the observation that blue has become exaggerated at the expense of other pattern elements. Black and orange account for a relatively small proportion of total body area, and cover less than one-sixth the area covered by blue (median values shown in Table 1). Although color patters vary significantly among populations, wild-type guppies typically have a far greater proportion of the body covered by orange and black spots than the values observed in this population (Alexander and Breden 2004; Kemp et al. 2008). It is intriguing that a male ornament of such importance to female choice in other populations (orange pigment) has become reduced to such an extent that it either covers a very small area of the body or is completely absent in the color pattern of individual males.

The exaggerated expression of blue and the corresponding female preference for this trait in the study population may be due to a number of non-mutually exclusive factors, including founder effects, female preferences, or ecological differences. Genetic founder effects in the introduced population could be responsible for the observed disparity between this population and others. If founding males had an unusually high expression of the trait and/or founding females had an unusually strong preference for the trait, this 
could be sufficient to drive the evolution of the trait, assuming genetic linkage between trait and preference (Houde 1994).

Table 1 Median values and standard errors of the median of male characters in Group A and Group $\mathrm{B}$, and results of $t$ tests comparing males from each group; blue area is the only character that is significantly different between the two groups

\begin{tabular}{lrrrc}
\hline Male character & Group A & Group B & \multicolumn{2}{l}{ Significance } \\
\cline { 4 - 5 } & Median $\pm \mathrm{SE}_{\mathrm{m}}$ & Median $\pm \mathrm{SE}_{\mathrm{m}}$ & $t$ & $P$ \\
\hline Blue area (\%) & $39.81 \pm 1.52$ & $30.14 \pm 1.14$ & 6.397 & $<0.001$ \\
Black area (\%) & $2.23 \pm 1.31$ & $1.37 \pm 0.47$ & 1.938 & $\mathrm{NS}$ \\
Orange area (\%) & $3.35 \pm 1.09$ & $3.19 \pm 0.97$ & 0.533 & $\mathrm{NS}$ \\
Caudal fin length (mm) & $8.15 \pm 1.89$ & $5.72 \pm 0.86$ & 2.051 & $\mathrm{NS}$ \\
Standard length (mm) & $16.79 \pm 0.46$ & $17.04 \pm 1.00$ & 0.542 & $\mathrm{NS}$ \\
\hline
\end{tabular}

Fig. 1 Average amount of time (mean and standard deviation) spent by females with males of Group A (more blue), Group B (less blue) and in the neutral (no choice) zone

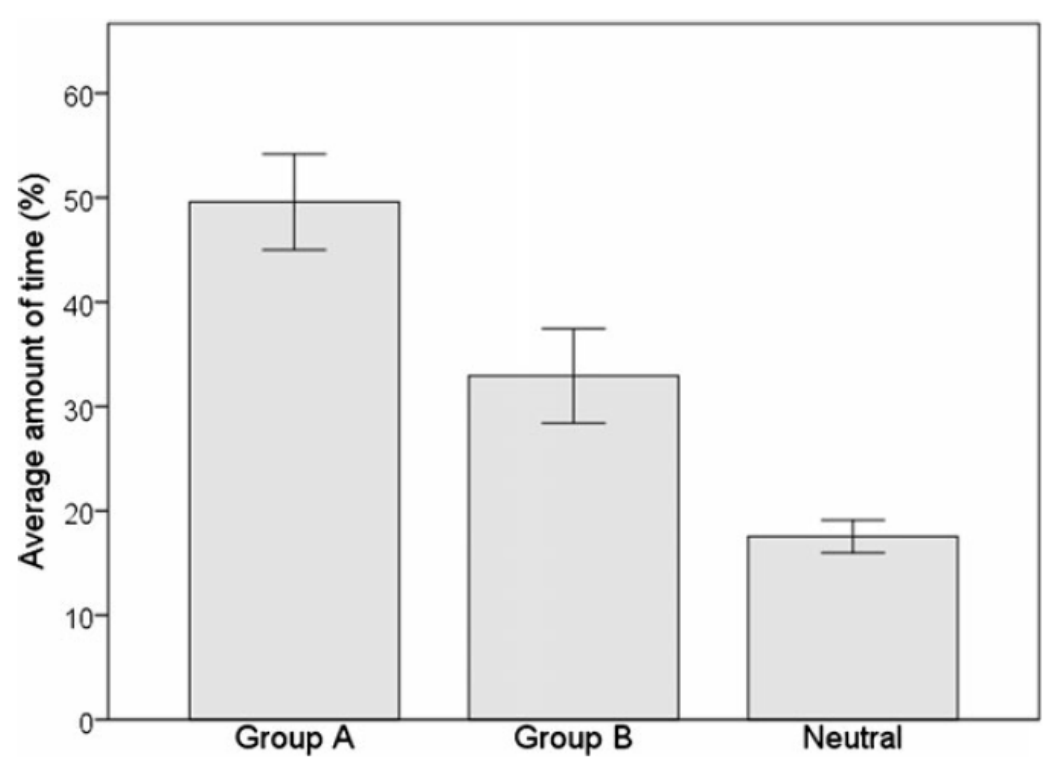

Alternatively, evolving female preferences may be responsible for the altered phenotype of Japan blue males. Sexual selection is known to be a strong driving force of male trait divergence (e.g., Uy and Borgia 2000; Maan and Seehausen 2011). If female Japan blue guppies developed a strong preference for blue coloration, this could explain both the high phenotypic expression of blue in males and the reduced expression of other, less preferred colors, which compete for space on the body surface.

A further possibility is that there has been selective pressure for an increase in blue in order to aid conspicuousness in the surrounding natural environment. Differences in the ecological environment of an organism can promote divergence and may ultimately lead to reproductive isolation (Rosenblum and Harmon 2010; Sobel et al. 2010; Riesch et al. 2011). In animals that rely on signaling systems for mate choice cues, any alteration of the environment under which signaling occurs can critically influence both the nature and perception of signals. Divergence in both mating signals and preferences as a result of ecological differences is referred to as sensory drive (Endler 1992, 1993), a process whereby male traits evolve to exploit the sensory capabilities of females, of which mating 
preferences are a by-product (Endler and Basolo 1998; Tobias et al. 2010; Egger et al. 2011). Colors that function as visual mate choice cues will have the greatest impact when they achieve maximum contrast with the background. According to the sensory bias hypothesis, signals that transmit more effectively in a particular environment are favored by selection (Endler 1992). That the evolution of visual signals may be strongly dependent on ambient lighting conditions is supported by empirical studies (e.g., Douglas et al. 2007; Doucet et al. 2007). Under such a scenario, blue coloration would be selected for if it is more conspicuous to females than other colors under local lighting conditions (Endler and Basolo 1998). Previous studies on fish have shown that clearer water with a higher transmission of short (blue) wavelengths is associated with the appearance of red color morphs, while heavily stained water with a lower transmission of short wave-lengths is associated with an increase in blue color morphs (Reimchen 1989; Fuller 2002). Furthermore, female guppies living in environments with a higher transmission of shorter wavelengths of light have a greater preference for males with blue and silver iridescent colors (Endler and Houde 1995). Light intensity does not only affect the physical appearance of males, but also their behavior. Males guppies exposed to lower levels of light are shown to increase their rates of display (Endler 1987; Archard et al. 2009) and to display at a closer range to the female (Long and Rosenqvist 1998). Further investigation is warranted in order to assess the natural conditions under which Japan blue guppies evolved, and to determine whether this has impacted the physical appearance as well as the behavior of the fish.

Not only lighting conditions but also other ecological factors may impose selective pressures on color pattern. Differences in predation pressure have been shown to cause a corresponding change in male coloration in guppies (Endler 1978). Males from high predation populations have fewer color spots, particularly blue and iridescent ones, and there is a closer match between spot size and gravel size in these populations (Endler 1980). Transplant experiments have also demonstrated that changes in predation pressure can cause guppy populations to evolve extremely rapidly (Magurran 1998), thus allowing populations to diverge in color pattern over relatively short time periods.

In conclusion, the results presented here indicate that the predominantly blue color pattern of male Japan blue guppies may have arisen as a result of female preferences. This is the first study to examine female preferences in this unusual feral population, and more studies are needed to further investigate the roles of mate choice as well as other factors in the evolution of these guppies.

\section{Acknowledgements}

We would like to thank Richard Knight for valuable comments and for providing the fish used in the experiments, as well as two anonymous reviewers for constructive comments on the manuscript. 


\section{References}

Alexander HJ, Breden F (2004) Sexual isolation and extreme morphological divergence in the Cumaná guppy: a possible case of incipient speciation. J Evol Biol 17:1238-1254

Archard GA, Cuthill IC, Partridge JC (2009) Light environment and mating behavior in Trinidadian guppies (Poecilia reticulata). Behav Ecol Sociobiol 64:169-182

Bagnara JT, Fernandez PJ, Fujii R (2007) On the blue coloration of vertebrates. Pigment Cell Res 20:14-26

Bischoff RJ, Gould JL, Rubenstein DI (1985) Tail size and female choice in the guppy (Poecilia reticulata). Behav Ecol Sociobiol 17:253-255

Brooks R, Caithness N (1995) Female choice in a feral guppy population: are there multiple cues? Anim Behav 50:301-307

Brooks R, Endler JA (2001) Direct and indirect sexual selection and quantitative genetics of male traits in guppies (Poecilia reticulata). Evolution 55:1002-1015

Doucet SM (2002) Structural plumage coloration, male body size, and condition in the blue-black grassquit. Condor 104:30-38

Doucet SM, Meadows MG (2009) Iridescence: a functional perspective. J R Soc Interface 6:S115-S132

Doucet SM, Montgomerie R (2003) Multiple sexual ornaments in satin bowerbirds: ultraviolet plumage and bowers signal different aspects of male quality. Behav Ecol 14:503-509

Doucet SM, Mennill DJ, Hill GE (2007) The evolution of signal design in manakin plumage ornaments. Am Nat 160:S63- S80

Douglas JM, Cronin TW, Chiou TH, Dominy NJ (2007) Light habitats and the role of polarized iridescence in the sensory ecology of neotropical nymphalid butterflies (Lepidoptera: Nymphalidae). J Exp Biol 210:788-799

Egger B, Klaefiger Y, Theis A, Salzburger W (2011) A sensory bias has triggered the evolution of egg-spots in cichlid fishes. PLoS One 6:e25601

Endler JA (1978) A predator's view of animal color patterns. Evol Biol 11:319-364

Endler JA (1980) Natural selection on color patterns in Poecilia reticulata. Evolution 34:7691

Endler JA (1983) Natural and sexual selection on color patterns in poeciliid fishes. Environ Biol Fish 9:173-190

Endler JA (1987) Predation, light intensity and courtship behaviour in Poecilia reticulata (Pisces: Poeciliidae). Anim Behav 35:1376-1385

Endler JA (1992) Signals, signal conditions, and the direction of evolution. Am Nat 139:S125S153

Endler JA (1993) Some general comments on the evolution and design of animal communication systems. Philos Trans R Soc Lond B 340:215-225

Endler JA, Basolo AL (1998) Sensory ecology, receiver biases and sexual selection. Trends Ecol Evol 13:415-420

Endler JA, Houde AE (1995) Geographic variation in female preferences for male traits in Poecilia reticulata. Evolution 49:456-468

Evans JP, Bisazza A, Pilastro A (2004) Female mating preferences for colourful males in a population of guppies subject to high predation. J Fish Biol 65:1154-1159 
Farr JA (1980) Social behavior patterns as determinants of reproductive success in the guppy, Poecilia reticulata Peters (Pisces: Poeciliidae): An experimental study of the effects of intermale competition, female choice, and sexual selection. Behaviour 74:3891

Fitzstephens DM, Getty T (2000) Colour, fat and social status in male damselflies, Calopteryx maculata. Anim Behav 60:851-855

Fuller RC (2002) Lighting environment predicts relative abundance of male color morphs in bluefin killifish populations. Proc R Soc Lond B 269:1457-1465

Godin JGJ, Herdman EJE, Dugatkin LA (2005) Social influences on female mate choice in the guppy, Poecilia reticulata: generalized and repeatable trait-copying behavior. Anim Behav 69:999-1005

Hill GE, Doucet SM, Buchholz R (2005) The effect of coccidial infection on iridescent plumage coloration in wild turkeys. Anim Behav 69:387-394

Houde AE (1987) Mate choice based upon naturally occurring color-pattern variation in a guppy population. Evolution 41:1-10

Houde AE (1994) Effect of artificial selection on male color patterns on mating preference of female guppies. Proc R Soc Lond B 256:125-130

Houde AE (1997) Sex, color, and mate choice in guppies. Princeton University Press, Princeton

Houde AE, Endler JA (1990) Correlated evolution of female mating preferences and male color patterns in the guppy Poecilia reticulata. Science 248:1405-1408

Karino K, Matsunaga $\mathrm{J}$ (2002) Female mate preference is for male total length, not tail length in feral guppies. Behaviour 139:1491-1508

Karino K, Shinjo S (2004) Female mate preference based on male orange spot patterns in the feral guppy Poecilia reticulata in Japan. Ichthyol Res 51:316-320

Karino K, Ishiwatari T, Kudo H, Sato A (2011) Female mate preference for a costly ornament in male guppies. Behav Ecol Sociobiol 65:1305-1315

Kemp DJ, Rutowski RL (2007) Condition dependence, quantitative genetics, and the potential signal content of iridescent ultraviolet butterfly coloration. Evolution 61:168-183

Kemp DJ, Vukusic P, Rutowski RL (2006) Stress-mediated covariance between nanostructural architecture and ultraviolet butterfly coloration. Funct Ecol 20:282-289

Kemp DJ, Reznick DN, Grether GF (2008) Ornamental evolution in Trinidadian guppies (Poecilia reticulata): insights from sensory processing-based analyses of entire colour patterns. Biol J Linn Soc 95:734-747

Kemp DJ, Reznick DN, Grether GF, Endler JA (2009) Predicting the direction of ornament evolution in Trinidadian guppies (Poecilia reticulata). Proc R Soc Lond B 276:43354343

Kodric-Brown A (1985) Female preference and sexual selection for male coloration in the guppy (Poecilia reticulata). Behav Ecol Sociobiol 17:199-205

Kodric-Brown A (1989) Dietary carotenoids and male mating success in the guppy: an environmental component to female choice. Behav Ecol Sociobiol 25:393-401

Kodric-Brown A (1993) Female choice of multiple male criteria in guppies: interacting effects of dominance, coloration and courtship. Behav Ecol Sociobiol 32:415-420 
Kodric-Brown A, Johnson SC (2002) Ultraviolet reflectance patterns of male guppies enhance their attractiveness to females. Anim Behav 63:391-396

Kodric-Brown A, Nicoletto PF (1996) Consensus among females in their choice of males in the guppy Poecilia reticulata. Behav Ecol Sociobiol 39:395-400

Lim MLM, Li DQ (2007) Effects of age and feeding history on structure-based UVornaments of a jumping spider (Araneae: Salticidae). Proc R Soc Lond B 274:569-575

Long KD, Houde AE (1989) Orange spots as a visual cue for female mate choice in the guppy (Poecilia reticulata). Ethology 82:316-324

Long KD, Rosenqvist G (1998) Changes in male guppy courting distance in response to a fluctuating light environment. Behav Ecol Sociobiol 44:77-83

Maan ME, Seehausen O (2011) Ecology, sexual selection and speciation. Ecol Lett 14:591602

MacLaren RD, Fontaine A (2012) Female preference for male lateral projection area in Poecilia reticulata. Environ Biol Fish 93:105-119

Magurran AE (1998) Population differentiation without speciation. Philos Trans R Soc Lond B 353:275-286

McGraw KJ, Mackillop EA, Dale J, Hauber ME (2002) Different colors reveal different information: how nutritional stress affects the expression of melanin- and structurally based ornamental plumage. J Exp Biol 205:3747- 3755

Miller LK, Brooks R (2005) The effects of genotype, age and social environment on male ornamentation, mating behavior, and attractiveness. Evolution 59:2414-2425

Møller AP, Petrie M (2002) Condition dependence, multiple sexual signals, and immunocompentence in peacocks. Behav Ecol 13:248-253

Price AC, Weadick CJ, Shim J, Rodd FH (2008) Pigments, patterns, and fish behavior. Zebrafish 5:297-307

Reimchen TE (1989) Loss of nuptial color in threespine stickle-backs (Gasterosteus aculeatus). Evolution 43:450-460 Reynolds JD, Gross MR (1992) Female mate preference enhances offspring growth and reproduction in a fish, Poecilia reticulata. Proc R Soc Lond B 250:57-62

Riesch R, Plath M, Schlupp I (2011) Speciation in caves: experimental evidence that permanent darkness promotes reproductive isolation. Biol Lett 7:909-912

Rosenblum EB, Harmon LJ (2010) "Same same but different": replicated ecological speciation at White Sands. Evolution 65:946-960

Sobel JM, Chen GF, Watt LR, Schemske DW (2010) The biology of speciation. Evolution 64:295-315

Tobias JA, Aben J, Brumfield RT, Derryberry EP, Halfwerk W, Slabbekoorn H, Seddon N (2010) Song divergence by sensory drive in Amazonian birds. Evolution 64:28202839

Uy JAC, Borgia G (2000) Sexual selection drives rapid divergence in bowerbird display traits. Evolution 54:273-278

Walling CA, Royle NJ, Lindström J, Metcalfe NB (2010) Do female association preferences predict the likelihood of reproduction? Behav Ecol Sociobiol 64:541548 